${ }^{I}$ Universidade Federal do Rio de Janeiro (UFRJ),

Programa de Pós-Graduação em Sociologia e Antropologia,

Rio de Janeiro, RJ, Brasil

carolcanascimento@gmail.com

Ana Carolina Nascimento'

\title{
CANTORIA DE REPENTE: PRÁTICA E REPRODUÇÃO SOCIAL
}

Sautchuk, João Miguel. (2012).

A poética do improviso: prática e habilidade no

repente nordestino. Brasília: Ed. UnB, 363p.

A poética do improviso: prática e habilidade no repente nordestino, de João Miguel Sautchuk, é resultado da sua tese de doutorado, defendida pelo Programa de Pós-Graduação em Antropologia Social da Universidade de Brasília. A tese recebeu o Prêmio Mais Cultura de Literatura de Cordel do Ministério da Cultura (categoria pesquisa) e menções honrosas no Concurso Sílvio Romero de Monografias sobre Folclore e Cultura Popular (IPHAN), no Concurso ANPOCS de Teses e Obras Científicas e no Prêmio CAPES de Tese.

Qualquer um que já tenha assistido a uma cantoria de repente fica intrigado com a capacidade dos poetas de criar versos no momento da apresentação, em rápida resposta ao oponente. Em pesquisa de campo em curso, conheci o repentista Sebastião
Marinho, natural de Solânea (PB), que vive em São Paulo há décadas. Ele costuma dizer que o público admirador da cantoria é formado em sua maioria por conhecedores: "Aquele indivíduo que nunca ousou fazer uma mísera quadra, jamais vai entender o sacrifício de um repentista".

$O$ repente é um gênero de poesia cantada presente em todos os estados do Nordeste do Brasil, e naqueles que receberam imigrantes nordestinos. Em duplas, os cantadores se enfrentam, alternando-se na criação de estrofes, a partir de rígidas regras de métrica e rima e respeitando a exigência de coerência temática (oração). O objetivo é convencer o público da superioridade sobre o parceiro.

A pergunta inicial do estudo aproxima-se da admiração comum aos ou- 
vintes da cantoria: como os repentistas conseguem compor suas estrofes em tão pouco tempo? Etnomusicólogo de formação, vindo de uma tradição disciplinar que considera que não há, na música ou nas artes verbais, improviso puro, mas sim a criação de textos originais a partir da relação com modelos estéticos preestabelecidos, o autor explora o improviso no repente como um conceito nativo.

Revisando a produção acadêmica sobre a cantoria nordestina, parte de importantes achados daqueles que se debruçaram anteriormente sobre este campo, principalmente os de Elisabeth Travassos, a quem presta homenagem na dedicatória. Percebendo que a maior parte dos estudos lança foco restritamente sobre os versos já prontos, Sautchuk dá um passo ao descrever etnograficamente o fazer poético, detalhando os processos e estratégias de composição e apresentação dos repentistas.

A estratégia de pesquisa de que lançou mão foi o aprendizado da cantoria. Na etnomusicologia o aprendizado prático da arte que se analisa é um método de pesquisa recomendado desde a década de ig6o. Porém para o repente tal projeto requer coragem, uma vez que seus detentores defendem que improvisar é um dom com o qual se nasce, não podendo ser aprendido. Enfrentando a descrença de boa parte dos interlocutores (o obstáculo sugere pistas que serão proveitosamente exploradas na seção sobre o aprendizado dos repentistas), o pesquisador definiu os lugares de seu trabalho de campo ao encontrar dois cantadores que se dispuseram a lhe ensinar, nas cidades de Fortaleza (CE) e Caruaru (PE), nas quais residiu ao todo por um ano (além de ter realizado visitas a outros 46 municípios em todo o país). Ao final do livro foi incluída uma pequena biografia de cada um dos informantes, situados em diferentes posições desta rede de relações: cantadores (de diversos status, condição social, faixas etárias e regiões de origem), declamadores, apologistas, promoventes, apresentadores de programas de rádio, produtores fonográficos. Outra opção corajosa, neste campo marcado por disputas, intrigas e maldizeres, e em que os interlocutores acompanham de perto a produção de pesquisadores, foi identificar, na grande maioria das situações que descreve, os nomes dos sujeitos envolvidos. Tal opção foi negociada com os envolvidos durante a pesquisa e escrita.

O encaminhamento teórico que o guiou foi a teoria da prática de Pierre Bourdieu. Sautchuk defende a atualidade da argumentação do sociólogo francês acerca das relações dialéticas entre as estruturas lógicas dos sistemas sociais e as disposições pelas quais tais estruturas são reproduzidas. O etnógrafo aprendiz de cantador percebe que "na cantoria há normas detalhadas de rima, métrica e coerência temática para a poesia, mas os repentistas dependem muito mais de uma maestria prática, baseada em padrões incorporados, do que de conhecimentos poéticos explícitos para improvisar seus versos" (p. 27).

A explicação do repente que os cantadores recorrentemente repetiam ao 
pesquisador dizia respeito às regras da rima ("não se rima 'mulhé' com 'café': 'mulher' rima com 'quer', 'café' com 'Assaré'”). O domínio desta norma depende do acesso à língua escrita, não alcançado igualmente por todos.

A métrica é referida como a quantidade de versos por estrofe e de sílabas por verso. Os cantadores dizem que há dezenas ou mesmo centenas de modalidades do repente. João Miguel descreve as regras das mais usadas (sextilhas, décimas, martelo agalopado etc.) e o livro vem acompanhado de um CD com gravações de cada uma delas. Por exemplo, sextilha é uma estrofe de seis versos, com sete sílabas cada, rimando entre si o segundo, o quarto e o sexto versos.

No primeiro capítulo, narrando cada passo de seu aprendizado, das percepções provocadas por seus erros e das lições ouvidas de seus mestres, explora a distância entre a descrição oficial das regras da cantoria, expressa em números de sílabas e linhas, e os fundamentos práticos do repente. O salto de sua compreensão é dado ao prestar atenção quando os cantadores dizem que "Ninguém conta as sílabas para fazer uma estrofe, a gente metrifica pela toada" ou "Cantar repente é como encher algum recipiente, quando se desmetrifica, se percebe que faltou ou sobrou enchimento" (p. 85). Toadas são as melodias sobre as quais os versos são compostos. Pertencem a um repertório compartilhado, e são acompanhadas por uma viola de dez cordas adaptada. O uso de metáforas quantitativas pelos cantadores para demonstrar a necessidade da corres- pondência entre a extensão dos versos e a das melodias leva o autor a concluir que o ritmo poético incorporado é o elemento primordial da habilidade do repentista. A inspiração para explorar esta hipótese vem da teoria de composição por fórmulas desenvolvida por Albert Lord em I960, sobre o método de composição de cantadores de poemas épicos na Iugoslávia.

No segundo capítulo são analisados relatos de cantadores sobre a infância e o início de carreira. O objetivo é entender como se tornaram poetas, pensar o processo de reprodução da cantoria e de reprodução de valores estruturais da vida social por meio da cantoria. As histórias trazem algumas regularidades estruturais, mas as dissonâncias não são deixadas de fora, abrindo espaço o tempo todo para matizar as reflexões do trabalho. Sendo o repente uma das diversões principais na localidade em que viviam, são recorrentes os relatos dos que na infância brincavam de ser cantador. Ouvindo e imitando o cantar gradativamente adquiriam o ritmo poético. Nestes jogos incorporava-se outro fundamento do repente: as habilidades, disposições e valores relacionados à disputa.

A maior parte dos repentistas defende que improvisar é um dom inato. Porém, à medida que o contato com o pesquisador se aprofundou, passaram a descrever um processo de aprendizado gradual, no qual contaram com ensinamentos dos mais antigos. Sautchuk chama a atenção para a necessária dinâmica de reconhecimento 
por parte dos colegas e ouvintes de que alguém é um cantador, não resultando de simples escolha e esforço individuais.

O terceiro capítulo parte da descrição etnográfica de uma cantoria de pé de parede no agreste pernambucano, da qual participaram cantadores de diferentes estratos. A situação é privilegiada para a observação, por evidenciar tensões e nuances do campo, diferenciações de prestígio e ganhos financeiros correspondentes aos espaços e redes de relação em que cada cantador consegue se inserir. $O$ pé de parede seria o arranjo mais frequente da prática, realizado em casas particulares, sítios ou bares, em que os cantadores atendem a pedidos de assuntos e modalidades feitos pelo público, que paga colocando dinheiro sobre uma bandeja. O olhar do pesquisador sempre inclui a interação da dupla de cantadores com o terceiro sujeito nesta relação: o público, sobre quem e para quem se canta. Afastando-se da dicotomia entre tradição e modernidade, reiterada por alguns pesquisadores, o autor enfoca a percepção dos cantadores sobre a consolidação de novos modos de fazer repente: grandes festivais (formalização da competição com júri), rádio e televisão, gravação de CDs e DVDs, o cantar de mesa em mesa em bares e praias no contexto das cidades, a presença nas feiras populares. A remuneração pela bandeja não permite aos cantadores saber de antemão quanto se vai ganhar, configurando uma situação de instabilidade profissional. A partir da década de I970 os cantado- res começam a se organizar (debatendo em congressos, formando associações), se esforçando para controlar o vínculo entre trabalho e remuneração, por exemplo, com a cobrança de um cachê fixo e a estipulação de um tempo de duração para a apresentação.

O capítulo seguinte vai tratar das relações de reciprocidade entre poetas, que devem retribuir convites para formar dupla em apresentações. Estas relações são analisadas no livro como trocas de dádivas, a partir das quais circulam cantadores, convites, cachês, e por meio das quais angaria-se prestígio e contatos. O lado oposto e indissociável das alianças são as exclusões, divisões e rivalidades. O sentido de peleja estrutura tanto a forma de composição e apresentação dos versos como a dinâmica das relações sociais entre os poetas.

O livro conclui propondo uma reflexão sobre a reprodução social: como valores sociais mais abrangentes se fazem presentes na cantoria e são engendrados por meio dela. Novamente explorando o rendimento analítico da observação de uma cantoria específica, desta vez entre um homem e uma mulher, em que o cantador elogiava a força como um atributo masculino, Sautchuk discute a divisão de gênero presente na afirmação da masculinidade pela ação do desafio e pelo conteúdo dos versos. Trazendo a experiência das mulheres, destaca as tensões que envolvem a participação feminina como cantadeiras, ouvintes e pesquisadoras.

Outra oposição, a de classe social, transparece no uso do conhecimento 
como capital no enfrentamento poético. Vale ressaltar que a maior parte dos cantadores mais antigos teve parco acesso à escolarização formal durante a infância e adolescência (o que não os impediu de dominar um amplo acervo de conhecimentos de origem erudita), enquanto entre os mais jovens cresce o número daqueles com diploma universitário e de pós-graduação.

A etnografia de João Miguel Sautchuk traz sensíveis contribuições ao campo de uma antropologia da prática. Em um contexto mais específico, no momento em que o repente está passando pelo processo de reconhecimento pelo Instituto do Patrimônio Histórico e Artístico Nacional como patrimônio cultural do Brasil, é de grande valia este livro, que divulga e instiga a reflexão sobre os mistérios desta arte.

Recebida em 29/04/20I6 Aprovada em 05/06/2016

Ana Carolina Nascimento é doutoranda e mestre pelo Programa de Pós-Graduação em Sociologia e Antropologia da UFRJ. 